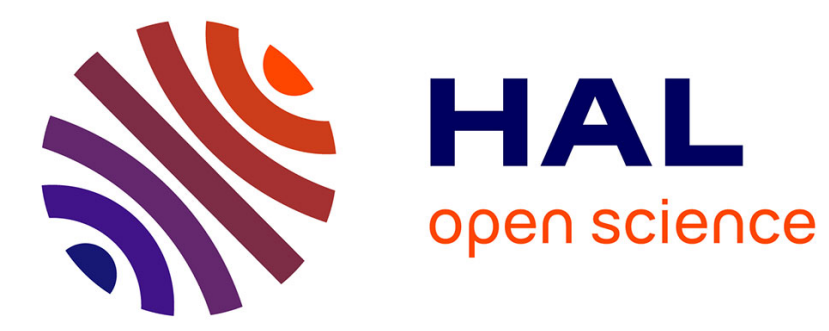

\title{
Sex Ratios under Asymmetrical Local Mate Competition: Theory and a Test with Parasitoid Wasps
}

David M Shuker, Ido Pen, Alison Duncan, Sarah E Reece, Stuart A West

\section{To cite this version:}

David M Shuker, Ido Pen, Alison Duncan, Sarah E Reece, Stuart A West. Sex Ratios under Asymmetrical Local Mate Competition: Theory and a Test with Parasitoid Wasps. The American Naturalist, 2005, 166, pp.301 - 316. 10.1086/432562 . hal-02353181

\section{HAL Id: hal-02353181 \\ https://hal.science/hal-02353181}

Submitted on 7 Nov 2019

HAL is a multi-disciplinary open access archive for the deposit and dissemination of scientific research documents, whether they are published or not. The documents may come from teaching and research institutions in France or abroad, or from public or private research centers.
L'archive ouverte pluridisciplinaire HAL, est destinée au dépôt et à la diffusion de documents scientifiques de niveau recherche, publiés ou non, émanant des établissements d'enseignement et de recherche français ou étrangers, des laboratoires publics ou privés. 


\title{
Sex Ratios under Asymmetrical Local Mate Competition: Theory and a Test with Parasitoid Wasps
}

\author{
David M. Shuker, ${ }^{1, \star}$ Ido Pen, ${ }^{2, \dagger}$ Alison B. Duncan, ${ }^{1, \ddagger}$ Sarah E. Reece, ${ }^{1, \S}$ and Stuart A. West ${ }^{1, \|}$
}

1. Institute of Evolutionary Biology, School of Biological Sciences, University of Edinburgh, West Mains Road, Edinburgh EH9 3JT, United Kingdom;

2. Theoretical Biology, Centre for Ecological and Evolutionary Studies, University of Groningen, NL-9751NN Haren, The Netherlands

Submitted December 17, 2004; Accepted May 25, 2005; Electronically published July 11, 2005

Online enhancement: appendix.

AвSTRACt: Sex ratio theory allows unparalleled opportunities for testing how well animal behavior can be predicted by evolutionary theory. For example, Hamilton's theory of local mate competition (LMC) is well understood and can explain variation in sex allocation across numerous species. This allows more specific predictions to be developed and tested. Here we extend LMC theory to a situation that will be common in a range of species: asymmetrical LMC. Asymmetrical LMC occurs when females lay eggs on a patch asynchronously and male offspring do not disperse, leading to relatively weaker LMC for males emerging from later broods. Varying levels of LMC then lead to varying optimal sex ratios for females, depending on when and where they oviposit. We confirm the assumptions of our theory using the wasp Nasonia vitripennis and then test our predictions. We show that females adjust their offspring sex ratios in the directions predicted, laying different sex ratios on different hosts within a patch. Specifically, there was a less female-biased sex ratio when ovipositing on an unparasitized host if another host on the patch had previously been parasitized and a less female-biased sex ratio on parasitized hosts if females also oviposited on an unparasitized host.

Keywords: Nasonia vitripennis, adaptation, clutch size, host choice, sex allocation.

\footnotetext{
* E-mail: david.shuker@ed.ac.uk.

† E-mail: penir@biol.rug.nl.

₹ E-mail: alison.duncan@ed.ac.uk.

s E-mail: sarah.reece@ed.ac.uk.

|| E-mail: stu.west@ed.ac.uk.
}

Am. Nat. 2005. Vol. 166, pp. 301-316. (c) 2005 by The University of Chicago. 0003-0147/2005/16603-40813\$15.00. All rights reserved.
Sex ratio theory provides a touchstone in the study of adaptation (Charnov 1982; Godfray 1994; Hamilton 1996; Frank 1998, 2002; Hardy 2002). In many cases, the fitness consequences of adjusting offspring sex ratios (proportion male) are relatively straightforward, and so it can be simple to predict how sex ratios should evolve. Overall, there is a very good qualitative understanding of the selective forces that influence sex ratios and the extent to which they apply in organisms ranging from parasitic protozoa to mammals. A major advantage of sex ratio theory is that a close and even quantitative fit can be expected between theory and data (Charnov 1982). This means that we have an excellent opportunity to use sex ratio as a model trait to address very general questions. In particular, to what extent and with what precision can we use the adaptationist approach to explain life-history evolution (Seger and Stubblefield 1996; West et al. 2000; Herre et al. 2001; West and Sheldon 2002)?

Here we are concerned with one of the best-studied areas of sex ratio evolution, Hamilton's theory of local mate competition (LMC). Hamilton (1967) was the first to show that when mating takes place between the offspring of one or a few mothers, before only the daughters disperse, a female-biased sex ratio is favored. Specifically, it can be shown that in a diploid, the evolutionarily stable strategy (ESS) sex ratio, $\hat{x}$, is given by $\hat{x}=(N-1) / 2 N$, where $N$ is the number of females that lay eggs per patch (Hamilton 1967; Taylor and Bulmer 1980), and that in haplodiploids, $\hat{x}=(N-1)(2-p) / N(4-p)$, where $p$ is the average level of inbreeding (Frank 1985; Herre 1985). The forces selecting for this female bias are extremely well understood and can be conceptualized with a number of equally valid approaches (Taylor 1981; Herre 1985; Frank 1986, 1998). LMC theory has been extremely successful in explaining sex ratio variation within and among species as well as facultative adjustment of offspring sex ratios in response to variable LMC (Charnov 1982; Hardy 2002).

However, previous work on LMC has generally assumed symmetrical mating opportunities within patches (Ham- 
ilton 1967; Werren 1980; Nunney and Luck 1988; Frank 1998). This will often not be the case, because females of many invertebrate species can lay eggs on patches sequentially, leading to the asynchronous emergence of individuals on those patches (Godfray 1994; West et al. 2005). If the early-emerging broods give rise to females who disperse after mating with males from their brood and those males remain on the patch, this will lead to an asymmetry in the level of LMC that males from different broods experience, or asymmetrical LMC. Specifically, males from broods laid later will experience decreased LMC because of the extra competition from the early males. We term this situation asymmetrical LMC to distinguish it from previous models for sequential oviposition in which emergence is synchronous and mate competition symmetrical (Suzuki and Iwasa 1980; Werren 1980; Nagelkerke 1994; Greeff 1997).

In this article, we develop and test theory for cases in which there is asymmetrical LMC. Our experimental work is carried out with the parasitoid wasp Nasonia vitripennis, a species that has been the focus of much empirical LMC research (see "Methods"). Our first aim is to develop theoretical models that predict how individuals should adjust their offspring sex ratio in response to asymmetrical LMC. This leads to novel predictions for how individuals should vary their offspring sex ratios across different hosts within a patch. Our second aim is to test whether the assumptions of our model apply to $N$. vitripennis. Specifically, we test whether mate competition is asymmetrical within patches, with earlier-laid males gaining a higher proportion of the matings. In addition, we test whether asymmetrical competition arises because males remain on patches when females from other broods are about to emerge and because females preferentially lay eggs on unparasitized hosts. Our third aim is to test the basic predictions of our model. Specifically, we determine whether females adjust their sex ratio in two ways in response to the likelihood that their brood will suffer asymmetrical LMC: first, by producing a less female-biased sex ratio when laying eggs on an unparasitized host when the other hosts on a patch were previously parasitized by another female, and second, by producing a less female-biased sex ratio when laying eggs on a previously parasitized host if females also lay eggs on an unparasitized host. Our experiments also allow us to test several other existing predictions for host choice and clutch size behavior (see below).

\section{Asymmetrical LMC Theory}

In this section and the online appendix, we extend previous LMC theory to allow for asymmetrical mate competition between the broods of different females. We use terminology associated with parasitoid wasps, but our pre- dictions apply to species with similar lifestyles in the numerous other taxa where LMC has been observed (Charnov 1982; West et al. 2005). The biological scenario that we are investigating is as follows. Two females lay eggs on a patch sequentially, with the second female arriving some time after the first female has left. The first female lays eggs on some of the hosts in the patch. The second female may lay eggs on these previously parasitized hosts and/or on the unparasitized hosts. When eggs are laid by both females on the same host (superparasitism), there is synchronous emergence of offspring because of the accelerated development of the second brood (Werren 1980). In contrast, when the second female lays eggs on a previously unparasitized host, these offspring will emerge later. This leads to asymmetrical LMC if the sons laid by the first female remain on the patch to mate with the daughters of the second female and the daughters of the first female disperse before the sons of the second female emerge.

The question that we ask is, how should the second female to visit the patch adjust her offspring sex ratio, depending on whether she is laying eggs in the parasitized or unparasitized hosts and the relative clutch sizes? To answer this, we consider the sex ratios produced on each host in a patch separately. We assume, first, a patchstructured population with LMC and random dispersal of mated females (island model of migration), second, that each patch contains two hosts that are visited sequentially by two females, and third, that female $i(i=1,2)$ lays $c_{i j}$ eggs on host $j(j=1,2)$ with sex ratio $x_{i \cdot}$. We allow for asymmetrical mate competition within a patch due to asynchronous emergence by assuming that female is son that was born on host $j$ has relative ability $a_{i j k}$ to mate with a host- $k$ female. It is this potential for asymmetrical mate competition between offspring laid on different hosts within a patch that makes our model differ from the muchstudied superparasitism model of Werren (1980) and Suzuki and Iwasa (1980).

Our model allows numerous possible situations to be investigated. In the appendix, we provide the full derivation of the model; ESS sex ratios for given values of the parameters were calculated numerically. Here we make predictions for scenarios that match the biology of the parasitoid wasp Nasonia vitripennis and other organisms with similar life histories. When particular parameter values are required for figures, we use those obtained from our experiments on N. vitripennis. For simplicity, we assume that the fitness of males does not depend on whether they were in the first or second brood laid on that host. Specifically, we assume that the relative fitness of males is 1.0 when competing for females that developed on their host $\left(a_{i 11}=a_{i 22}=1\right), h_{1}$ for males from the first host when competing for females from the second host $\left(h_{1}=a_{i 12}\right)$ and $h_{2}$ for males from the second host when competing for 
females from the first host $\left(h_{2}=a_{i 21}\right)$. The relative mating abilities $h_{1}$ and $h_{2}$ will often be correlated, because factors such as degree of emergence asynchrony will influence both, but $h_{1}$ will generally be greater than $h_{2}$.

Consider the case when the first female lays eggs on one host and the second female lays eggs on the other host $\left(c_{11}>0 ; c_{12}=0 ; c_{21}=0 ; c_{22}>0\right)$. We are able to make two predictions for the evolutionarily stable strategy (Maynard Smith 1982) offspring sex ratio of the second female $\left(\hat{x}_{22}\right)$.

1. If the females lay clutches of equal size, then the second female's sex ratio is predicted to become less female-biased as the relative mating ability of males to mate females from other hosts increases (increasing $h_{1}$ or $h_{2}$; fig. 1). This occurs because it increases the marginal fitness of producing sons by either reducing competition between them (increasing $h_{1}$ ) or providing more females for them to mate (increasing $h_{2}$ ).

2. If the clutch sizes on the two hosts differ, then the second female is predicted to lay an increasing proportion of males as the relative size of the clutch she lays decreases (fig. 2). This is analogous to the standard prediction from LMC theory that females should produce a less femalebiased sex ratio as their relative contribution of offspring to the patch decreases (Werren 1980; Frank 1985, 1987; Yamaguchi 1985; Stubblefield and Seger 1990).

These predictions could be tested in several ways. The most simple would be to test whether the second female lays a less female-biased sex ratio on an unparasitized host if the other host on the patch was previously parasitized. More subtle tests of these predictions could be conducted by varying the relative mating success $\left(h_{1}\right.$ and $\left.h_{2}\right)$ or the

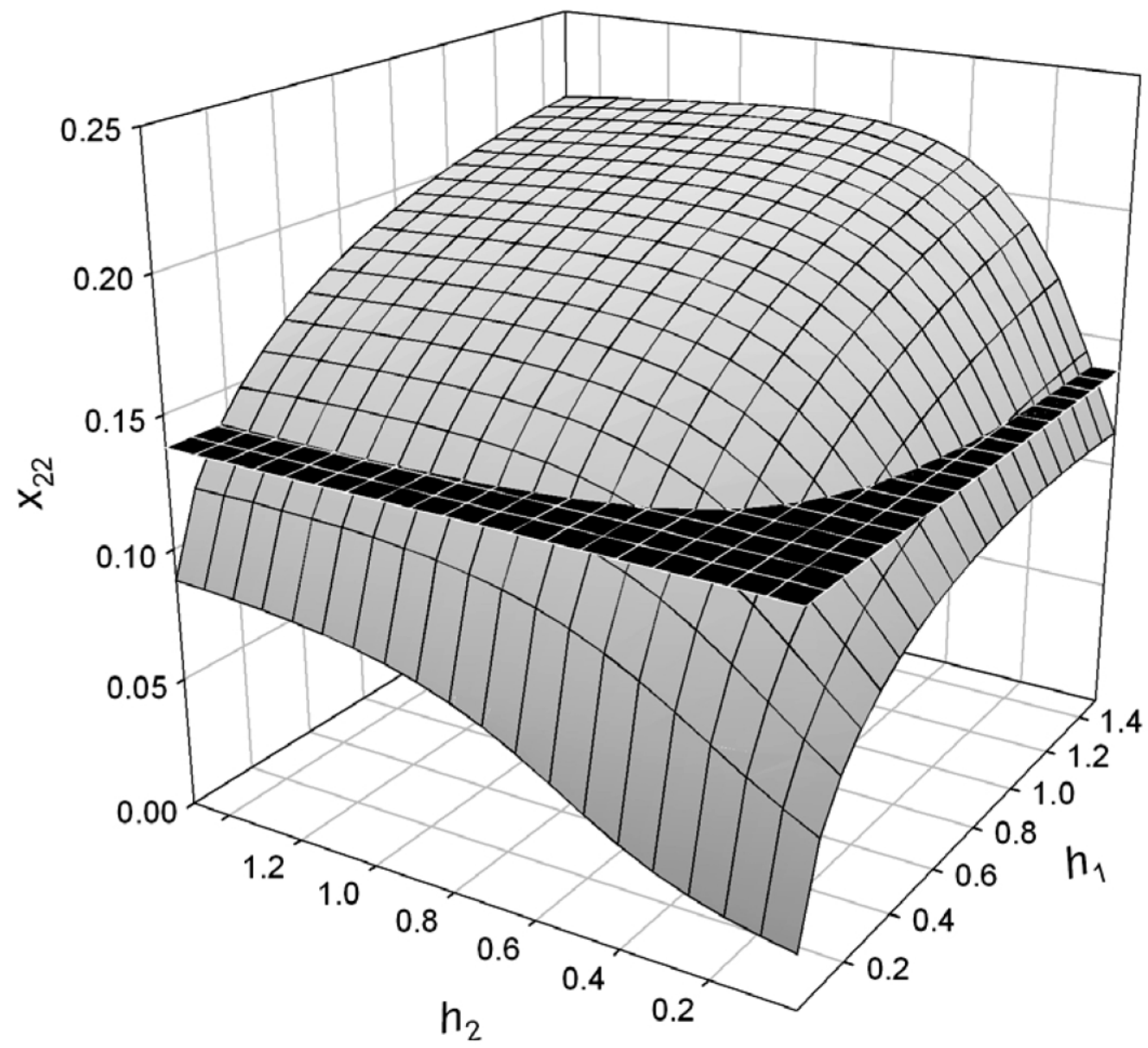

Figure 1: Evolutionarily stable strategy (ESS) sex ratio for a focal female laying on an unparasitized host in a patch when the other host has been previously parasitized. The ESS sex ratio $\left(\hat{x}_{22}\right)$ is plotted against the relative mating abilities of males from each host mating with females from the other host. The relative mating ability of males from the first host with females from the second host is given by $h_{1}$, and the relative mating ability of males from the second host with females from the first host is given by $h_{2}$. A less female-biased sex ratio is predicted as both $h_{1}$ and $h_{2}$ increase. Parameters used were $c_{11}=c_{22}, c_{12}=c_{21}=0, x_{11}=0.138$, and $F=0.31$. 


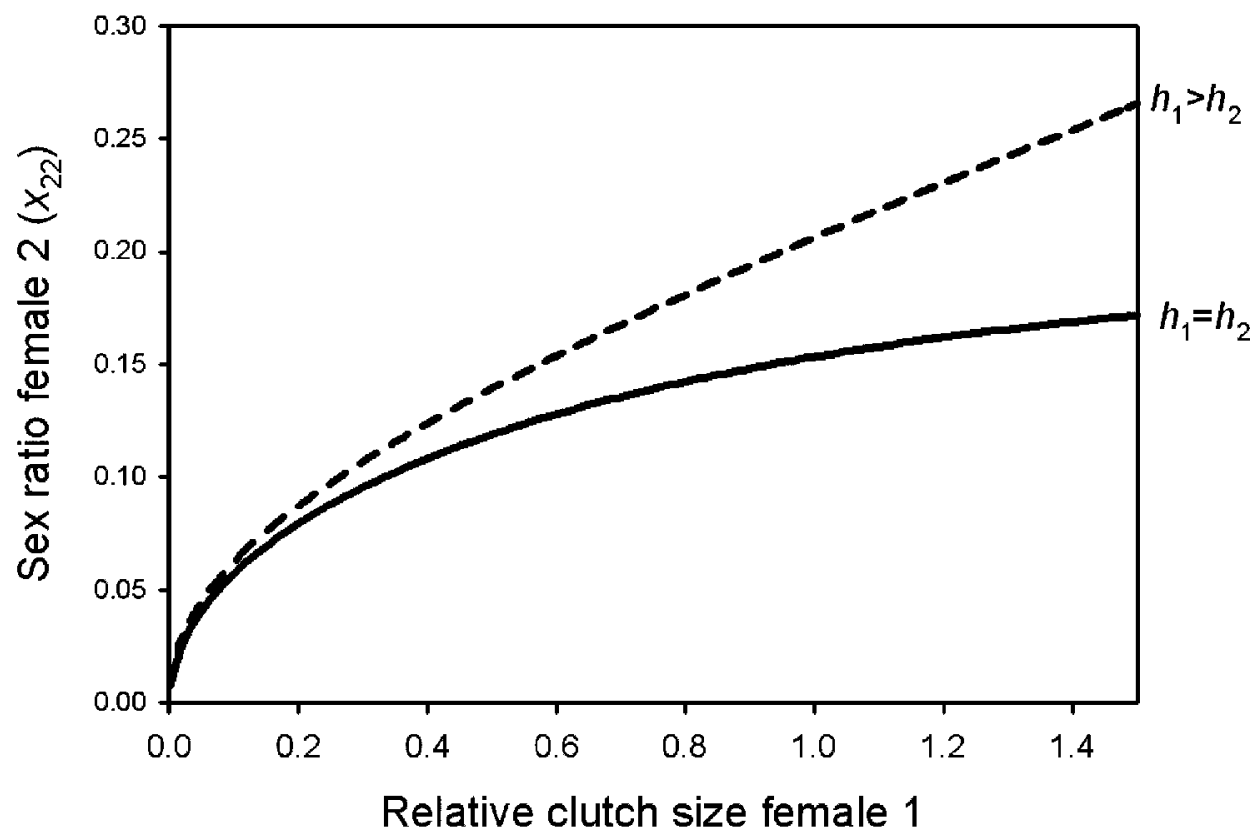

Figure 2: Evolutionarily stable strategy (ESS) sex ratio for a focal female laying on an unparasitized host in a patch when the other host has been previously parasitized. The ESS sex ratio $\left(\hat{x}_{22}\right)$ is plotted against the relative clutch size of the first female, defined as the clutch size laid by the first female divided by the clutch size laid by the second female on the unparasitized host $\left(c_{11} / c_{22}\right)$. A less female-biased sex ratio is predicted as the relative clutch size of the first female increases. The solid and dashed lines represent $h_{1}=h_{2}=1$ and $h_{1}>h_{2}\left(h_{1}=0.757, h_{2}=0.192\right)$, respectively. Parameters used were $c_{22}=31.07, c_{12}=c_{21}=0, x_{11}=0.138$, and $F=0.31$.

size of the clutch laid by the first female and determining whether females adjust their behavior accordingly. For example, increasing the time between the two females visiting the patch would lead to a decrease in both $h_{1}$ and $h_{2}$.

Now consider the case when the first female lays eggs on one host and the second female lays eggs on both hosts $\left(c_{11}>0 ; c_{12}=0 ; c_{21}>0 ; c_{22}>0\right)$. This is a more complicated scenario because the mating success of sons produced by the second female depends on which host they are laid on. In this case, we obtain the following predictions.

3. The second female is predicted to produce different sex ratios on the two hosts, with a more female-biased sex ratio on the unparasitized host $\left(\hat{x}_{21}>\hat{x}_{22}\right)$. Indeed, for many parameter values, the second female is predicted to produce only daughters on the unparasitized host $\left(\hat{x}_{22}=0\right.$; fig. 3$)$. This occurs because of the higher marginal fitness of sons laid on the first host $\left(h_{1}>h_{2}\right)$.

4. The ESS sex ratio produced by the second female on the parasitized host $\left(\hat{x}_{21}\right)$ is positively correlated with the clutch size that the second female produces on the unparasitized host $\left(c_{22}\right.$; fig. 3$)$. This is because the female is preferentially producing daughters on the unparasitized host.

We conclude this section with two points that relate our model to LMC theory more generally. First, asymmetrical LMC should be seen as another factor to add to the list of selective forces that can lead to individuals on the same patch producing different sex ratios. Other factors include those that have gained empirical support, such as variable clutch sizes or fecundity (Werren 1980; Yamaguchi 1985) and immigration status (Taylor and Crespi 1994), and those that have not gained empirical support, such as relatedness to mates or other females (Reece et al. 2004; Shuker et al. 2004a, 2004b). Second, the predictions of our model rely on the same underlying forces as previous LMC theory (Frank 1998). The novelty of introducing asymmetry is that it alters the strength of these forces differently for broods on different hosts on a patch. This means that, contrary to previous theory, individuals can be predicted to produce different offspring sex ratios on different hosts within the same patch. This can lead to counterintuitive predictions. For example, prediction 4 is in the opposite direction from predictions from variable fecundity models, where producing more offspring leads to a more femalebiased sex ratio (Yamaguchi 1985; Stubblefield and Seger 1990; Frank 1998); the difference arises because we are considering each host individually, not just the whole patch, and so split sex ratios are favored (see "Discussion"). 


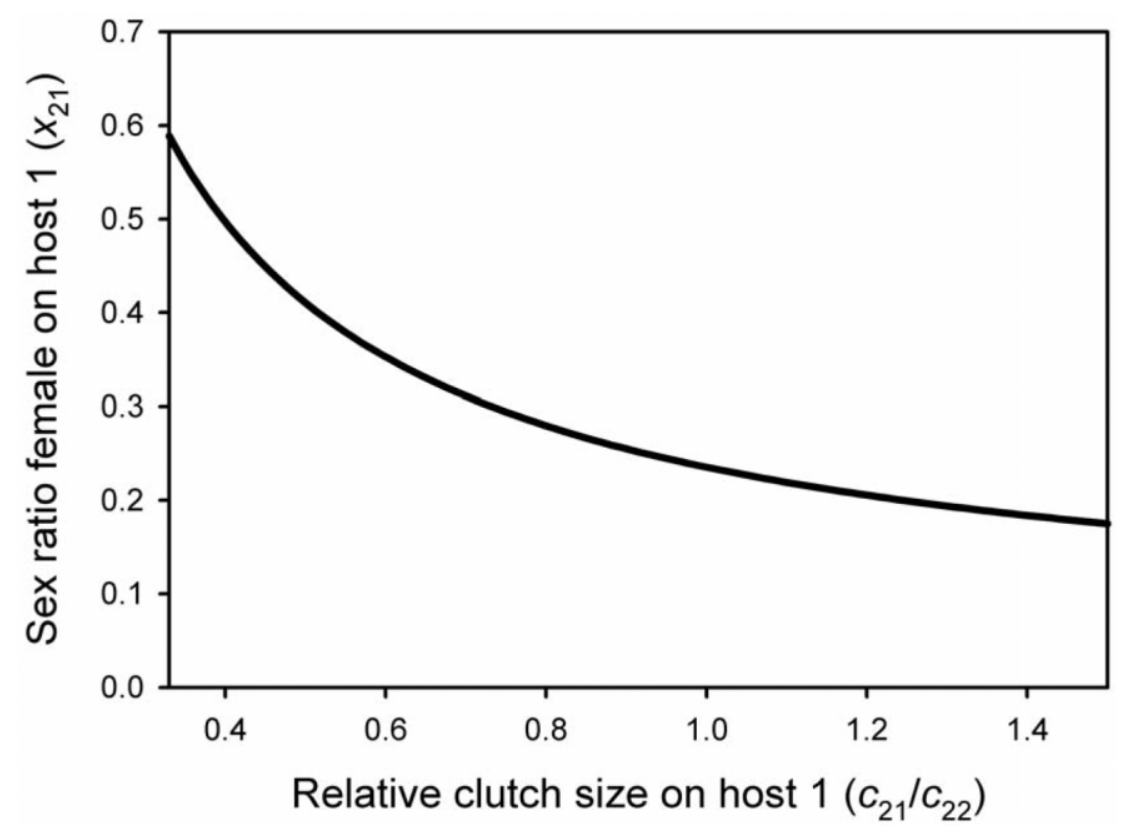

Figure 3: Evolutionarily stable strategy (ESS) sex ratio for a focal female laying on the previously parasitized host in a patch when this female has also oviposited in the previously unparasitized host. The ESS sex ratio $\left(\hat{x}_{21}\right)$ is plotted against the relative clutch size on the parasitized host, defined as the clutch size laid by the second female on the parasitized host divided by the clutch size laid by the second female on the unparasitized host $\left(c_{21} / c_{22}\right)$. A less female-biased sex ratio is predicted as a greater proportion of eggs on the patch from the focal female are laid on the unparasitized host (reducing $\left.c_{21} / c_{22}\right)$. The ESS sex ratio predicted on the unparasitized host is not plotted because it is always to produce only daughters $\left(\hat{x}_{22}=\right.$ 0 ). Parameters used were $c_{11}=22.52, c_{22}=31.07, c_{12}=0, x_{11}=0.138, F=0.31, h_{1}=0.757$, and $h_{2}=0.192$.

\section{Methods}

\section{Study Organism}

Nasonia vitripennis (Hymenoptera: Chalcidoidea) is a gregarious parasitoid wasp of large dipteran pupae (Whiting 1967). The mating system is characterized by local mate competition (LMC), with males emerging first and then mating with emerging females. Females typically mate only once before they disperse to find new oviposition sites. Males have small wings and are unable to fly, remaining at the site of adult emergence to compete with each other for matings. Females typically lay clutches of up to 40 eggs and limit oviposition in previously parasitized hosts (superparasitism) if possible. When superparasitism occurs within $48 \mathrm{~h}$ or so, broods from the different females (but same host) emerge synchronously (Werren 1980). Females do not oviposit on a host if host quality has deteriorated because larvae are already feeding in the host (Werren 1984). Since N. vitripennis is haplodiploid, sex ratio can be facultatively altered by females choosing whether or not to fertilize an egg (producing diploid females or haploid males, respectively), and females respond to both the presence of other females ovipositing on a patch and the presence of eggs already laid in a host when allocating sex
(Wylie 1966, 1976; Werren 1980, 1983, 1984; Orzack 1990; King and Skinner 1991; Orzack et al. 1991; King et al. 1995; Flanagan et al. 1998; Shuker and West 2004).

For the experiments described below, we used wasps from strain HV6, generated from wasps recently collected from the field (collected in the summer of 2002 from four bird boxes in Hoge Veluwe, Netherlands, by L. W. Beukeboom) and also from the laboratory red-eye mutant marker strain STDR. The red-eye strain was used to allow us to generate experimentally parasitized hosts such that we could follow the sex ratios of individual wild-type (black-eye) females. We also used the red-eye strain in the mating experiments to allow us to identify which male a female mated with. All wasps were maintained before experiments in mass culture, with Calliphora vomitoria pupae as hosts, at $25^{\circ} \mathrm{C}, 16 \mathrm{~L}: 8 \mathrm{D}$ light conditions. Under these conditions, males emerge after approximately 13 days, with females emerging soon after.

\section{Testing Assumptions I: Asymmetrical Mate Competition}

We first tested whether there is a mating advantage to the males that are laid and develop first on a patch. Specifically, we followed the mating success of males laid by two fe- 
males from the different strains and measured how this varied as the time between the two females visiting the patch changed, leading to changes in the emergence times of the two broods. We therefore varied emergence times by varying when hosts were parasitized. Females from both strains were allowed to emerge and mate in their massculture stocks for 3 days before being isolated and pretreated. Pretreatment consisted of individual females being given a fresh host for $24 \mathrm{~h}$, after which the host was removed and the females were provided with honey solution for a further $24 \mathrm{~h}$. This pretreatment allows host feeding and provides resources for egg maturation. We then gave each female a single host to parasitize for $24 \mathrm{~h}$. Approximately 150 females of each genotype (black-eye wild-type and red-eye mutant) were used to produce parasitized hosts. In both experiments, we then placed two hosts together in a $25 \times 75-\mathrm{mm}$ vial, one parasitized by a wildtype female and one parasitized by a red-eye female, so that each mating group consisted of wild-type and redeye males and females; all mating groups that did not contain all these types of individuals because of oviposition failure or female virginity were discarded. Just before emergence of the first offspring, one-way exit tubes were fitted to allow wasps to disperse from the natal patch. We collected mated females from the mating groups as they dispersed through the exit tubes at regular intervals. Since the red-eye mutant allele is recessive to the wild-type allele, female offspring from a red-eye mother that has mated with a wild-type male will be wild-type. Because of haplodiploidy, all sons of red-eye females will have red eyes, since they do not have a father. To produce hosts that would produce offspring on different days, we collected either wild-type (experiment 1) or red-eye (experiment 2) females over a 3-day period and again pretreated them and supplied them with hosts on the appropriate days as above.

Asymmetrical mate competition: late emergence. In this experiment, either the wasps emerged synchronously from the two hosts in each patch (treatments A and B), or the red-eye offspring emerged second. In treatment $\mathrm{C}$, wildtype individuals emerged $24 \mathrm{~h}$ before the red-eye offspring; in $\mathrm{D}$, they emerged $48 \mathrm{~h}$ before; and in $\mathrm{E}$, they emerged $72 \mathrm{~h}$ before. Treatment A represented a control for the effects of "host territory," with both hosts being broken open 2 days before wasp emergence (12 days postparasitization) and the wasp pupae from both hosts being mixed together. In treatments B-E, wasps emerged from intact hosts as usual. We recorded the number, sex, and genotype of all individuals in the mating groups in treatments A and $\mathrm{B}$ in order to consider the effect of the proportion of males that were red-eye males on mating patterns and also the effect of the operational sex ratio (proportion of all individuals that were males in the mating group). Because of continual dispersal of individuals of both sexes from the natal patches, these ratios are difficult to quantify over time in treatments $\mathrm{C}-\mathrm{E}$, and we do not consider them. We collected up to five red-eye females from each mating group after mating and individually gave each two fresh hosts to oviposit in. The offspring from these hosts were then sexed and genotyped by eye color. In total, we examined offspring from 604 females from 124 mating groups.

Asymmetrical mate competition: early emergence. This experiment was similar to the previous experiment, except that this time red-eye offspring were manipulated to emerge up to $72 \mathrm{~h}$ before wild-type offspring. Again we included a control in which both hosts were opened. We set up slightly fewer replicate mating groups per treatment, with offspring from up to six females per mating group genotyped by eye color to assign paternity. In total, we examined offspring from 551 females from 99 mating groups.

In both experiments, we assigned broods as being fathered by either a red-eye male or a wild-type male or as the result of polyandry (with female offspring of both genotypes being present). Our primary interest is the extent to which females from one host are mated by males from the same host. Because polyandry was relatively rare, for the present analysis we included polyandrous females with females who mated with only a red-eye male.

\section{Testing Assumptions II: Male Patch-Leaving Decisions}

We then tested whether asymmetrical LMC could arise as a result of adaptive mate location behavior by males. Specifically, asymmetrical LMC would be more likely to occur if males choose to remain on a patch when females are about to emerge from other hosts on the patch rather than move more widely to search for other females. We performed two experiments to test male responses to soonto-emerge adult females.

Male patch-leaving decisions: time to adult emergence. In the first experiment, we tested virgin males with hosts that were unparasitized, parasitized but with only wasp eggs or larvae present, or parasitized with wasp pupae or adults close to emergence from the host. We created virgin males by placing unmated HV6 females individually with two hosts. Following emergence of the male offspring, we randomly chose one male per tube for use in the experiment. Males were used within $24 \mathrm{~h}$ of emergence and for one trial only. The experiment had five treatments. Males were placed in $75 \times 10$-mm glass tubes with two hosts that were unparasitized (control, treatment A), parasitized $24 \mathrm{~h}$ previously (treatment $\mathrm{B}$ ), parasitized 6 days previously (treatment C), parasitized 13 days previously (treatment $\mathrm{D}$ ), or parasitized 14 days previously (treatment E). Hosts were 
parasitized by mated females (one female ovipositing per host), and we checked all hosts afterward to confirm presence of eggs/larvae/pupae. In no cases did any wasps emerge from experimental hosts before or during the experiment (i.e., the hosts were intact). We placed a oneway exit tube on each tube, leading to an inverted glass tube. The exit was made from a $1-\mathrm{mL}$ plastic pipette tip, cut to size, with a small piece of masking tape wrapped around the wide end to ensure a snug fit. Males were considered to have left the patch when they entered the upper tube. We then placed the experimental tubes at $25^{\circ} \mathrm{C}$ in an incubator in light conditions, and the males were scan sampled every $10 \mathrm{~min}$ for $4 \mathrm{~h}$. We tested 11 males in each treatment, except for treatment $\mathrm{D}$, in which 10 males were tested.

Male patch-leaving decisions: sex ratio of emerging adults. In the second experiment, we tested mated males, and we also varied the sex ratio of the brood emerging from the hosts, creating hosts with female-biased sex ratios, intermediate sex ratios, or all-male broods. In this experiment, we used wasps from strain HV287 (from the same location as the HV6 wasps). The same general methods were used as for the previous experiment. Mated males were obtained from mass culture within $24 \mathrm{~h}$ of emergence. In this experiment, we generated hosts parasitized either 13 days before the experiment (giving us hosts with wasp pupae or eclosing adults inside) or 2 days before the experiment (giving us hosts with early-instar larvae inside), and we manipulated the sex ratio in the hosts such that the brood sex ratios were female-biased, generated by placing a single mated female with a host as above; intermediate, generated by placing $10-15$ mated females in a $25 \times 75-\mathrm{mm}$ glass tube with 10 fresh hosts to parasitize for $24 \mathrm{~h}$; or all male, generated by taking female pupae from mass culture before adult emergence and keeping them separately as virgins before giving them each a host to parasitize. This gave us six treatment combinations. For completeness, we also generated 50 replicates of two controls, the first with no host present and the second with an unparasitized host present. As before, all hosts were checked to confirm presence of larvae/pupae, yielding sample sizes ranging from 32 to 47 per treatment combination and a total sample size of 246. Again, no wasps emerged before the males were presented with the hosts. The sex ratios in the hosts were also checked by randomly taking 20 of the experimental hosts per treatment group and allowing them to go through to emergence. The female-biased sex ratios were approximately 0.1 , the intermediate sex ratios approximately 0.4 , and the all-male sex ratios contained only males, as expected. This time, we scan sampled the males every 15 min for $3 \mathrm{~h}$.

\section{Testing Predictions: Sex Ratio and Asymmetrical LMC}

We then tested whether female wasps adjusted their behavior as predicted by theory. Do females alter their sex ratio behavior depending on both the host on which they are laying and any other hosts in the patch? We examined the behavior of females when they where allowed to lay eggs on a patch with two unparasitized hosts, one parasitized and one unparasitized host, or two parasitized hosts. This experiment allowed us to test several existing predictions from host choice, clutch size, and sex ratio theory as well as our asymmetrical LMC model. Specifically, we predict that females should preferentially oviposit in unparasitized rather then parasitized hosts (Charnov and Stephens 1988); lay larger clutches in unparasitized hosts (Godfray et al. 1991; Wilson 1994); lay a clutch size in parasitized hosts that is negatively correlated with the number of eggs that have been previously laid in that host (Godfray et al. 1991; Wilson 1994); lay a less female-biased sex ratio in unparasitized hosts when the other host on the patch has been parasitized (this article); lay a more female-biased sex ratio in parasitized hosts as the ratio of the clutch size produced by the second female to that produced by the first female increases (Suzuki and Iwasa 1980; Werren 1980); and lay a more male-biased sex ratio on a parasitized host when also laying on an unparasitized host in the same patch (this article). Furthermore, in addition to these qualitative tests of theory, we are able to use the parameter estimates from our earlier experiments to quantitatively test whether the sex ratio shifts are of the magnitude predicted by our asymmetrical LMC model.

We allowed wasps from HV6 to emerge and mate for $48 \mathrm{~h}$ before isolating 200 females for pretreatment. During the second day of pretreatment, we gave single fresh hosts to 200 individual mated red-eye STDR females for them to parasitize (hereafter called preparasitized). After pretreatment, we assigned approximately $60 \mathrm{HV} 6$ females to one of three treatments: two unparasitized hosts (treatment A), one preparasitized (by red-eye females) and one unparasitized host (treatment B), and two preparasitized (by red-eye females) hosts (treatment $\mathrm{C}$ ). For $1 \mathrm{~h}$, we kept each female and the hosts in a $75 \times 25$-mm glass tube with a foam bung, after which the foam bung was replaced with a one-way escape tube consisting of a rubber bung with a narrow glass tube, which led up into another glass tube. This allowed females to disperse from the experimental patch after oviposition and/or avoid superparasitism. After $24 \mathrm{~h}$, we removed all females, and the hosts were incubated individually at $25^{\circ} \mathrm{C}$. After approximately 3 weeks, all offspring had emerged and died, and we counted the number of male and female HV6 and redeye offspring. We discarded any replicates in which HV6 mothers failed to produce females, indicating possible vir- 
ginity, as well as any replicates in which it was found that the hosts were not preparasitized by red-eye females as expected. In total, the sample sizes for the three treatments were 58,47 , and 35 , respectively.

\section{Statistical Analysis}

Unless stated otherwise, we carried out all analyses utilizing standard generalized linear model methods (Crawley 2002). Throughout, we consider the sex ratio as the proportion of offspring that are male. Proportion data, such as sex ratios, fraction of males staying on a patch, and fraction of females that mated with a red-eye male, are characterized by binomially distributed data, and so we analyzed them using binomial errors and logit link functions (Crawley 2002; Wilson and Hardy 2002). Our general approach was to use generalized linear models with all the main effects and interactions fitted, followed by model simplification to test the significance of the changes in deviance associated with removing main effects and interaction terms (Crawley 2002). Differences between treatment levels were tested by collapsing levels together and seeing if there was a significant change in the deviance explained by the model. Problems can arise in significance testing with binomial errors if the data are overdispersed; after fitting the full model, we examined the data for overdispersion by dividing the residual deviance by the residual degrees of freedom to give the dispersion parameter (Crawley 2002). Limited overdispersion (dispersion parameter of $<4$ ) can be accounted for by rescaling the residual deviance by the dispersion parameter and using $F$-tests to test the significance of changes in deviance. This was done throughout. In addition, we checked model fit by examining the distribution of residuals. All analyses were carried out using S-Plus 6 (Insightful Corporation, Seattle).

\section{Results}

\section{Testing Assumptions I: Asymmetrical Mate Competition}

We carried out two experiments to test whether asynchronous oviposition on different hosts in a patch would lead to asymmetrical mate competition. Our results suggest that this occurs and that its importance decreases as the gap in emergence time between the hosts increases (fig. 4).

Asymmetrical mate competition: late emergence. There was a significant effect of treatment on the proportion of red-eye females mated by red-eye males $(F=3.31$, $\mathrm{df}=4,119, P=.01$; fig. $4 A$ ). If the red-eye brood were timed to emerge $24 \mathrm{~h}$ after the wild-type brood, fewer redeye females were mated by males from their own brood than if the broods hatched together (from intact hosts) or more asynchronously. For the two treatments in which broods were manipulated to hatch synchronously (control [A] and B), red-eye males were in the minority, making up $43.0 \%$ and $38.5 \%$ of the males, respectively. There was a significant positive effect of the proportion of competing males that were red-eye on the proportion of red-eye females mated by red-eye males $(F=34.81, \mathrm{df}=1,46$, $P<.0001)$. There was also a significant difference between the two treatments $(F=11.57, \mathrm{df}=1,46, P=.001)$. Therefore, more females were mated by males from their own brood if the hosts were left intact, compared to the control treatment, in which hosts were opened and the broods mixed, consistent with there being a host territory effect leading to nonrandom mating and/or some mating occurring within the host. There was no effect of operational sex ratio on patterns of mating for these two treatments $(F=0.26, \mathrm{df}=1,45, P=.61)$.

Asymmetrical mate competition: early emergence. Treatment again significantly influenced which males a red-eye female mated with $(F=27.02, \mathrm{df}=4,94, P<.0001$; fig. $4 B)$. If red-eye offspring were manipulated to emerge 48 $72 \mathrm{~h}$ before wild-type offspring, then all females were mated by red-eye males from their own hosts. For the two synchronously emerging treatments (treatments B and control $[\mathrm{A}]$ ), significantly more red-eye females were mated by wild-type males. There was no significant difference in proportion of red-eye females mated by redeye males between these two treatments (simplifying the model by collapsing these treatments, $F=1.29$, df $=$ $1,95, P=.26$ ), although the difference is in the direction consistent with the significant result in the previous experiment. For these two treatments, there was also no effect of operational sex ratio on proportion of red-eye females mated by red-eye males ( $F=0.01, \mathrm{df}=1,34, P=.94)$, but there was again a significant positive effect of the proportion of males in the mating group that were red-eyes $(F=24.84, \mathrm{df}=1,36, P<.0001)$. In this experiment, the numbers of red-eye and wild-type males were more even, with red-eyes making up $52.8 \%$ and $48.5 \%$ of the males in treatments B and control (A), respectively.

\section{Testing Assumptions II: Male Patch-Leaving Decisions}

Male patch-leaving decisions: time to adult emergence. Virgin males were significantly more likely to stay for $4 \mathrm{~h}$ on patches that contained hosts with females close to emergence (treatments $\mathrm{D}$ and $\mathrm{E}, \chi_{1}^{2}=8.77, P=.003$; fig. $5 A$ ). There were no significant differences among treatments A-C $\left(\chi_{1}^{2}<0.01, P>.99\right)$ or between treatments $\mathrm{D}$ and $\mathrm{E}$ $\left(\chi_{1}^{2}=0.40, P=.53\right)$.

Male patch-leaving decisions: sex ratio of emerging adults. Mated males were significantly more likely to stay on 
A
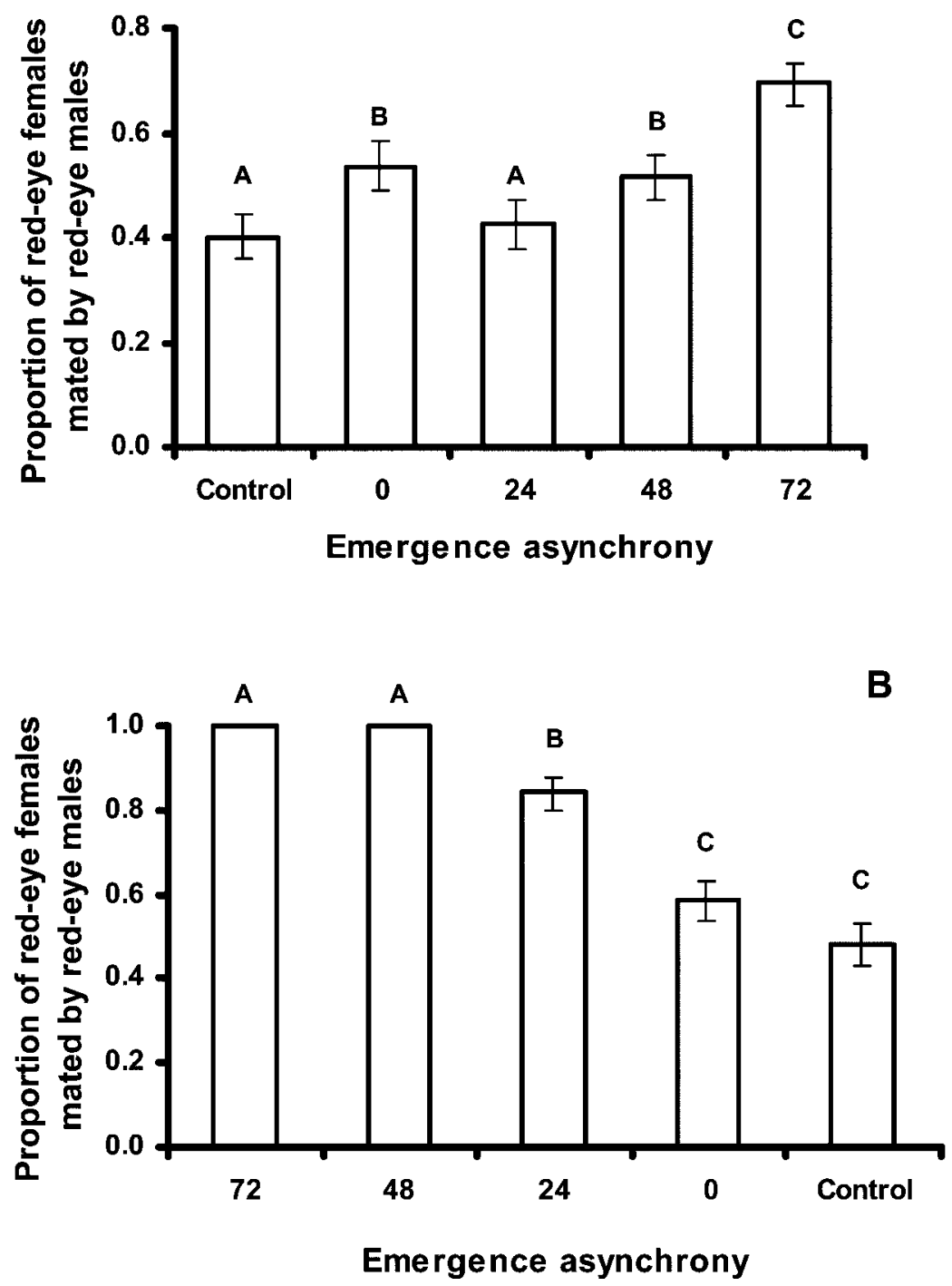

Figure 4: Proportion of females (red-eye) mated by males (red-eye) from the same host when the emergence asynchrony (hours) of broods is varied. $A$, Red-eye offspring emerge up to $72 \mathrm{~h}$ after wild-type HV6 offspring. Results marked $A$ and $B$ are nonsignificantly different: $P=.09$. Those marked $B$ and $C$ are significantly different: $P=.002 . B$, Red-eye offspring emerge up to $72 \mathrm{~h}$ before wild-type HV6 offspring. Results marked by letters are significantly different: $P<.001$. In both cases, an increase in emergence asynchrony leads to a higher proportion of mating between individuals from the same host. Comparison of $A$ and $B$ shows that males mate a higher proportion of the females from their own host when theirs is the first brood to emerge.

patches that contained hosts with females close to emergence (time of parasitism, $\chi_{2}^{2}=9.83, P=.002$; fig. $5 B$ ). There was also a highly significant effect of sex ratio of the brood within hosts on whether a male stayed $\left(\chi_{2}^{2}=\right.$ $34.69, P<.0001)$ and a highly significant interaction between time of parasitism and brood sex ratio $\left(\chi_{2}^{2}=\right.$ $12.45, P<.002)$, such that sex ratio was relevant for the 13-day-old brood but not the 2-day-old brood. There was no significant difference between the two control treatments in proportion of males staying, with $24 \%$ of males staying with an unparasitized host and $12 \%$ of males staying if there were no hosts present $\left(\chi_{1}^{2}=2.48, P=.12\right)$. There was also no difference between the three recently parasitized treatments and the pooled controls $\left(\chi_{3}^{2}=\right.$ 

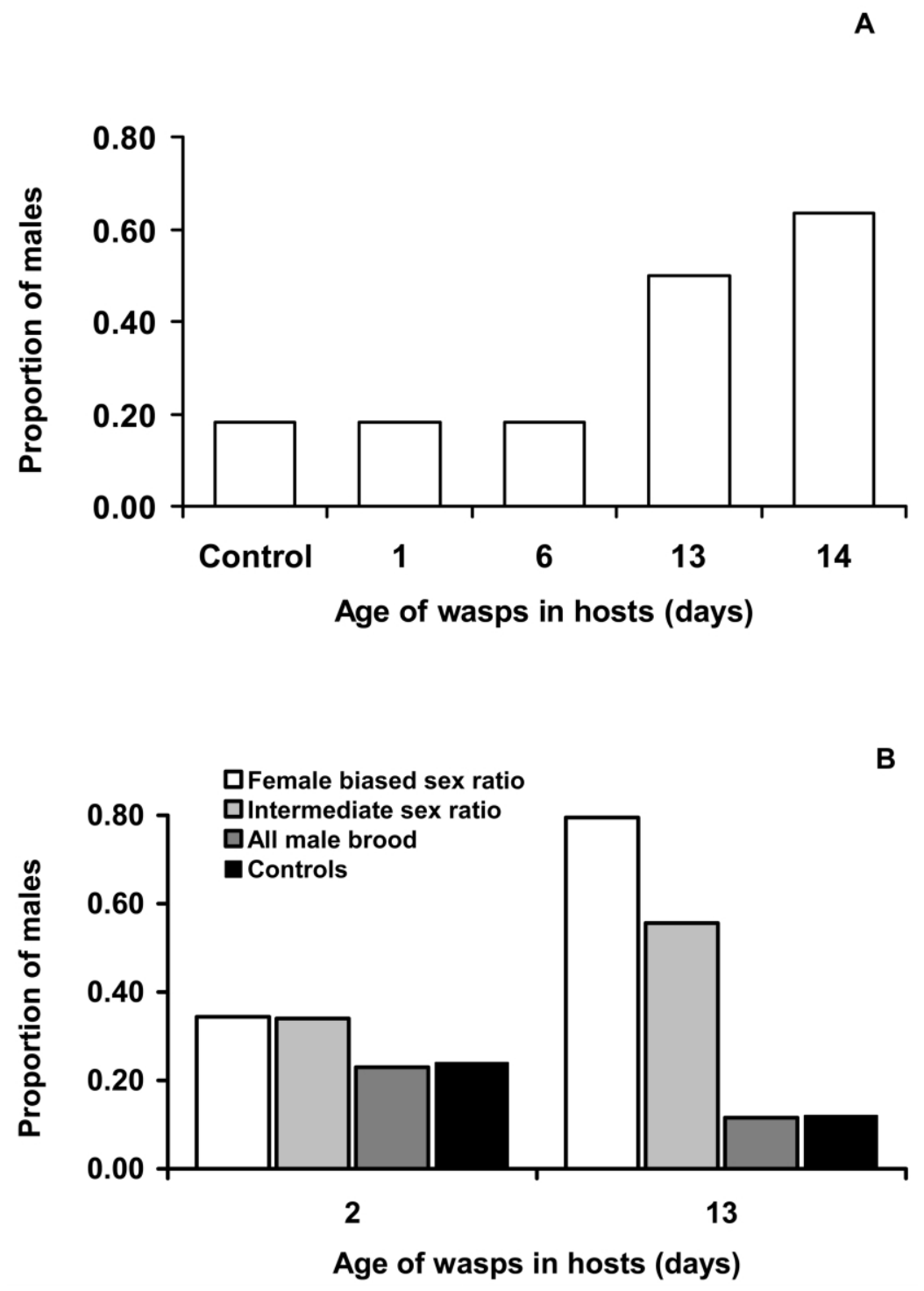

Figure 5: Proportion of males remaining on a patch versus the contents of parasitized hosts on that patch. A, Proportion of males remaining on the patch for $4 \mathrm{~h}$ versus the age in days of the wasps in the host. Control hosts were unparasitized. $B$, Proportion of males staying on a patch for $3 \mathrm{~h}$ versus the age and sex of wasps in the host. The two control columns are unparasitized hosts (left) and no hosts present (right). In both cases, males were more likely to remain on the patch when there were females about to emerge.

$6.20, P=.10)$ or between the all-male brood treatment when hosts had been parasitized 13 days before and controls $\left(\chi_{1}^{2}=0.95, P=.33\right)$.

\section{Testing Predictions: Sex Ratio and Asymmetrical LMC}

Oviposition preferences. As predicted, females preferentially oviposited in unparasitized hosts. In terms of overall female oviposition preference, 57 out of 58 (98.3\%) females oviposited if both hosts were unparasitized, 46 out of 47
(97.9\%) females oviposited if one host was unparasitized and one host preparasitized, and 29 out of 35 (82.9\%) females oviposited if both hosts preparasitized. Females were therefore less likely to oviposit if there were no unparasitized hosts present (Fisher's exact test comparing treatments $\mathrm{A}$ and $\mathrm{B}$ with $\mathrm{C}, P=.003$ ), although clearly the majority of females did still oviposit. There was also a highly significant difference between treatments in oviposition pattern if we compare the proportions of females who oviposited in one or both hosts, with females in treat- 
ments $\mathrm{B}$ and $\mathrm{C}$ more likely to oviposit in one host than those in treatment $\mathrm{A}\left(\chi_{2}^{2}=17.48, P=.0002\right.$; fig. $\left.6 A\right)$. Within treatment $B$, females who only oviposited on one host before dispersing did so nonrandomly, with 19 out of 20 females ovipositing on the unparasitized host (binomial test, $P<.001)$.

Furthermore, when females were limited to superparasitizing within treatment $\mathrm{C}$, they chose the host that resulted in lower larval competition. Of the 13 females who only oviposited on one host, 12 of them oviposited on the host with the fewest red-eye offspring inside (binomial test, $P=.004)$. The overall number of red-eye larvae in the two hosts did not influence the likelihood of ovipositing on one or both hosts for treatment $\mathrm{C}$ females, however (logistic regression, $P=.79$ ).

Clutch size. As predicted, females laid smaller clutches in parasitized hosts. This result held whether considering all treatments (one-way ANOVA, $F=31.27$, df $=2,127$, $P<.001$; Tukey's HSD showed that all three treatments differed significantly from each other, $P<.05$; fig. $6 B$ ) or just within treatment $B$, where individuals had the opportunity to oviposit on parasitized and unparasitized hosts (all females: $t=9.70, \mathrm{df}=70, P<.0001$; only females who oviposited in both parasitized and unparasitized hosts: paired $t$-test, $t=7.82$, df $=25, P<.0001$; clutch sizes in parasitized and unparasitized hosts were not significantly correlated for this subset of females who laid eggs in both: $r=-0.27, N=26, P=.19$ ). Furthermore, while clutch sizes did not differ significantly between parasitized hosts in treatments B and C $(t=0.08$, $\mathrm{df}=54, P=.94)$, the clutch size in unparasitized hosts in treatment B was significantly greater than that in unparasitized hosts in treatment A ( $t$-test with ln-transformed data to homogenize variances, $t=4.96, \mathrm{df}=98, P<$ .001 ), and this result was independent of whether a female also laid a clutch in the preparasitized host $(t=0.32$, $\mathrm{df}=43, P=.75)$.

As predicted, when ovipositing on preparasitized hosts, a female laid a clutch whose size was negatively correlated with the clutch size previously laid on those hosts. This result was highly significant in treatment $C$ (linear regression, $\beta=-0.76, \mathrm{SE}=0.17, F=20.03$, df $=1,43$, $P<.001, R^{2}=0.32$; fig. $\left.6 C\right)$ but marginally nonsignificant in treatment $\mathrm{B}(\beta=-0.39, \mathrm{SE}=0.20, F=3.85$, $\mathrm{df}=$ $\left.1,25, P=.06, R^{2}=0.13\right)$.

Sex ratio. As predicted, females adjusted their sex ratio depending on whether they were ovipositing in a parasitized or an unparasitized host and also on whether the other host in the patch was parasitized or unparasitized (fig. 7; comparing across the three treatments: $F=$ 38.31, $\mathrm{df}=2,127, P<.0001$; no effect of clutch size: $F=0.49$, df $=1,126, P=.48)$. First, as previously predicted, females laid more female-biased sex ratios when ovipositing in unparasitized hosts. This result held when comparing across treatments (treatment A, with two unparasitized hosts, vs. treatment $\mathrm{C}$, with two parasitized hosts: $F=86.63$, df $=1,82, P<.0001$; fig. 7 ) or within treatment $B$, in which females were able to oviposit on both types of host $(F=15.87$, $\mathrm{df}=1,50, P=.0002$; fig. 7 ; no effect of female identity or clutch size, $P>.6$ ). Second, as predicted by our asymmetrical LMC theory, females adjusted the sex ratio they laid in a host in response to whether other hosts on the patch had been previously parasitized. Considering females laying eggs on an unparasitized host when the other host on the patch was parasitized (treatment $\mathrm{B}$ ), the offspring sex ratio was significantly less female-biased if the other host on the patch was unparasitized (treatment A) but more female-biased if laid on only parasitized hosts (treatment $\mathrm{C} ; F=$ 36.80, df $=2,102, P<.0001$; no effect of clutch size, $P>.9)$.

When ovipositing in preparasitized hosts, females adjusted their offspring sex ratio in response to the size of the clutch previously laid on that host, but the extent to which they did this depended on whether the other host on the patch was also parasitized. Considering treatment $\mathrm{B}$ females who oviposited in preparasitized hosts and also treatment $\mathrm{C}$ females, the final minimal adequate model included a weak treatment effect $(F=4.77, \mathrm{df}=1,53$, $P=.03$ ), with treatment $\mathrm{B}$ females having a more malebiased sex ratio than treatment $\mathrm{C}$ females, and also a weak positive effect of the clutch size of the (red-eye) brood previously laid in that host $(F=4.01, \mathrm{df}=1,53, P=.05$; fig. 8). Two first-order interactions (treatment $\times$ clutch size and treatment $\times$ red-eye clutch size) were on the borderline of significance $(P=.05$ and .06 , respectively), suggesting that the association between sex ratio and these clutch sizes differs between treatments, with female sex ratios being more influenced by red-eye clutch size in treatment $\mathrm{B}$ than in treatment $\mathrm{C}$ (fig. 8). The ratio of red-eye to wild-type clutch sizes was not significant and so was not included in the minimal adequate model $(F=2.48$, $\mathrm{df}=1,53, P=.12)$. Therefore, in this experiment, there is a weak effect of red-eye clutch size on focal female sex ratio, but this is for the most part independent of the focal female's own clutch size.

\section{Quantitative Fit to Asymmetrical LMC Theory}

Using the data from the experiments reported above (figs. 4,5 , and 7 ), we can generate quantitative predictions for the expected sex ratios to see how closely the empirical data fit the predictions. Our parameter estimates for when the second female lays eggs only on the unparasitized host are $c_{11}=22.52, c_{22}=31.07, c_{12}=c_{21}=0, x_{11}=0.138$, $F=0.31, h_{1}=0.757$, and $h_{2}=0.192$. In this case, the 

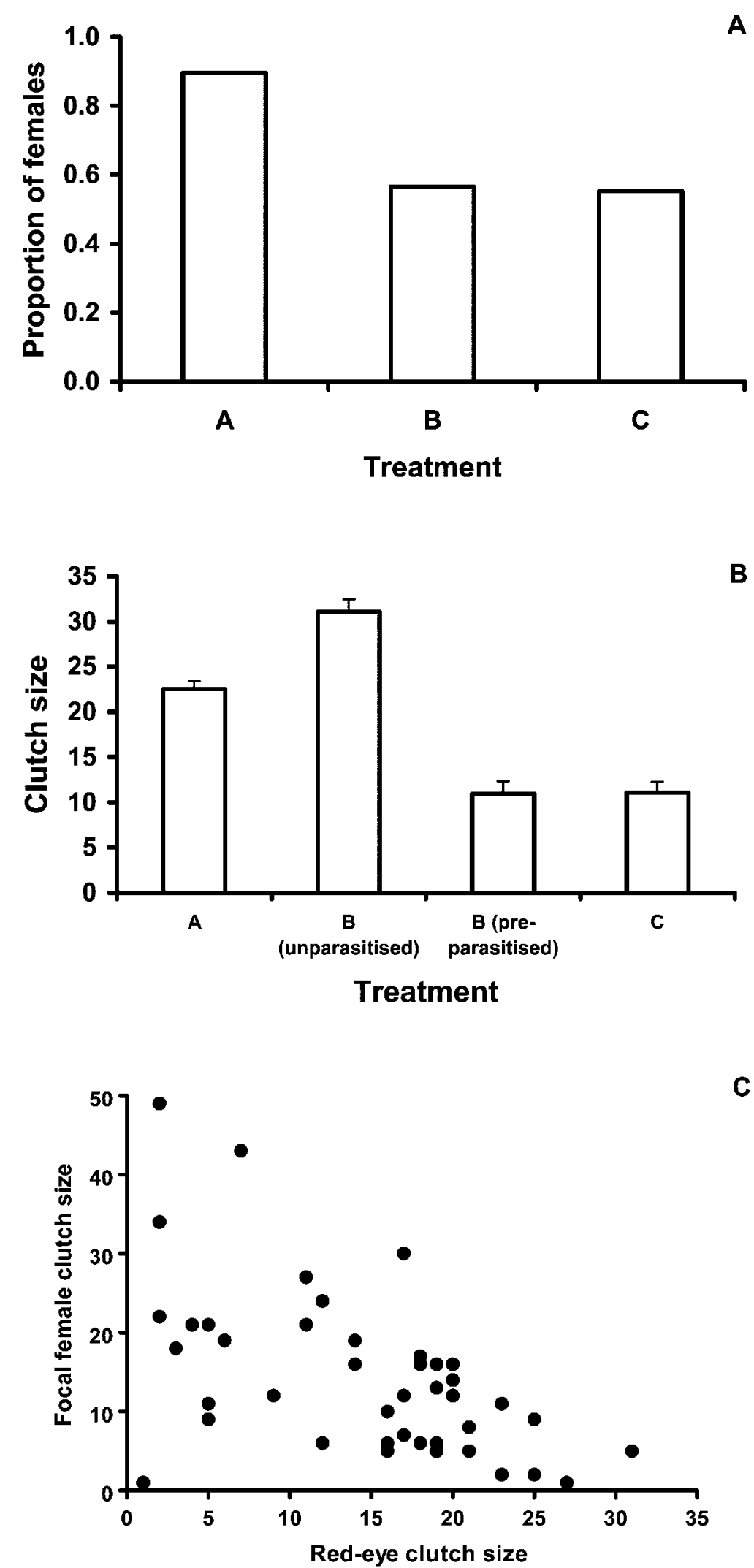
Figure 6: Oviposition decisions and patch treatment. A, Proportion of focal females ovipositing in both hosts with respect to patch treatment. $B$, Mean focal female clutch size (per host) with respect to patch treatment. $C$, Relationship between red-eye clutch size and superparasitizing focal females in treatment C. (In treatment A, both hosts were unparasitized; in treatment B, one of two hosts was preparasitized; in treatment C, both hosts were preparasitized.) Females were more likely to lay eggs on unparasitized hosts, laid larger clutches on unparasitized hosts, and laid clutches whose size was negatively correlated with the number of eggs already on the host in previously parasitized hosts.

ESS sex ratio for the second female to lay on the unparasitized host is $\hat{x}_{22}=0.14$ (calculated in Maple; see the appendix for details). The empirical estimate was 0.256 , with $95 \%$ confidence intervals ranging from 0.237 to 0.276 ; the predicted value is clearly outside these confidence intervals. When the second female lays eggs on both hosts, the ESS sex ratio for the unparasitized host is always $\hat{x}_{22}=0.0$ (i.e., all females); however, females do not produce these predicted all-female broods if they use both hosts.

\section{Discussion}

We have extended LMC theory to allow for asymmetrical mate competition between the offspring laid by different females on a patch. This is likely to occur in many species when females visit and lay eggs on a patch sequentially. We then tested the assumptions and predictions of our model in the parasitoid wasp Nasonia vitripennis. We found that asymmetrical LMC can occur and that its importance is increased by mate location behavior by males and host selection behavior by females. In addition, females adjusted their offspring sex ratios in the directions predicted, producing different sex ratios on different hosts in a patch. Furthermore, our results also supported several theoretical predictions that had previously been made for the evolution of host choice and clutch size.

\section{Does Asymmetrical LMC Occur?}

The results from our two mating experiments show that mate competition may be asymmetrical if there are broods from multiple hosts present on a patch (fig. 4). First, mating may not be as random if hosts are intact when compared to the degree of random mating if pupae from different broods are mixed. This confirms a host territory effect that had been observed previously, with males being more likely to remain where they have previously obtained matings (i.e., on the surface of the host from which they emerge) rather than search the patch for matings (van den Assem et al. $1980 a, 1980 b$ ). There is also the possibility of a limited amount of within-host mating between males

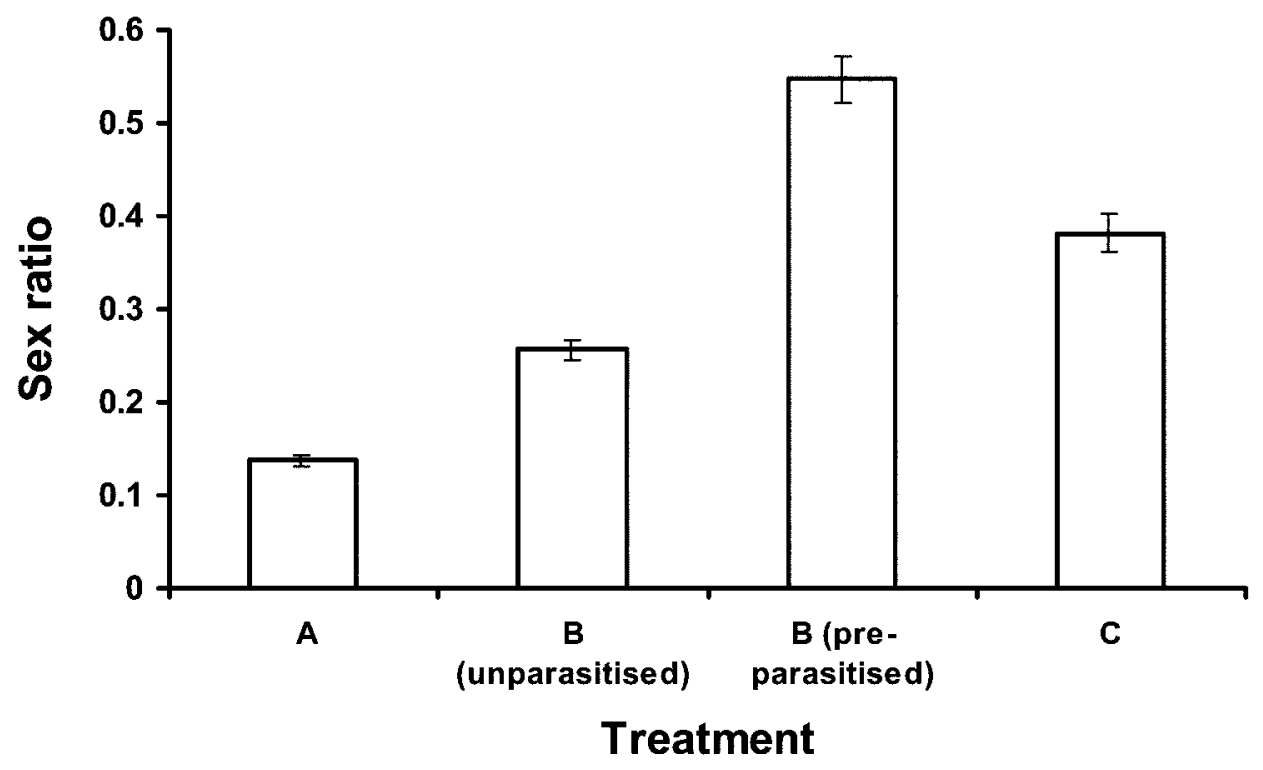

Figure 7: Sex ratio of focal females with respect to patch treatment (in treatment A, both hosts were unparasitized; in treatment B, one of two hosts was preparasitized; in treatment C, both hosts were preparasitized). Error bars represent binomial standard errors. Females adjusted their sex ratios on a host depending on whether the other host on the patch was parasitized, laying a less female-biased sex ratio on an unparasitized host if the other host was parasitized and a less female-biased sex ratio on a parasitized host if the other host was unparasitized. 


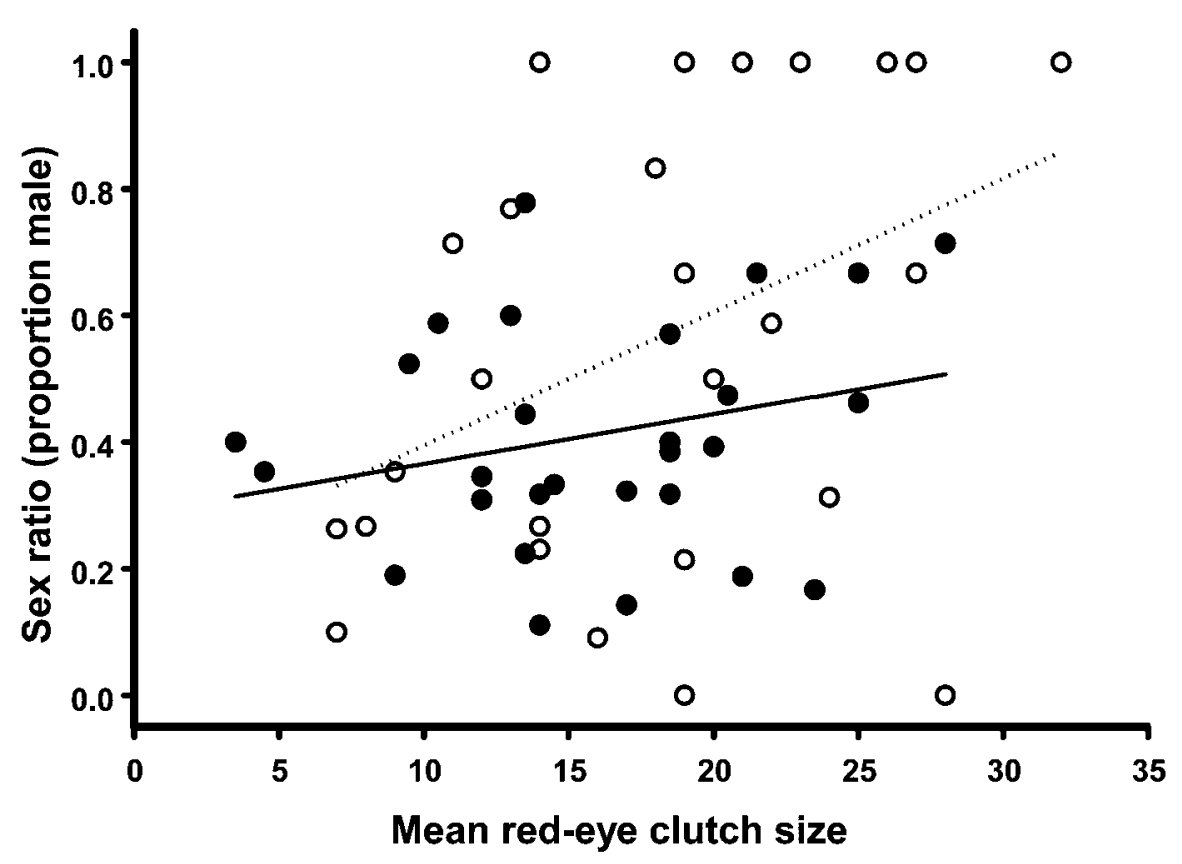

Figure 8: Relationship between mean red-eye clutch size and sex ratio of focal wild-type females for females in treatment $\mathrm{C}$ (both hosts preparasitized; filled circles) and for females in treatment B that oviposited in preparasitized hosts (open circles). Regression lines represent ordinary least squares regression lines for illustration (dotted line for treatment B, solid line for treatment C). When laying eggs on a parasitized host, a female laid a sex ratio that was both less female-biased and positively correlated with the number of eggs previously laid in the host, if the other host on the patch was unparasitized.

and females before emergence, although the extent of this in N. vitripennis is thought to be extremely limited (Drapeau and Werren 1999). Second, if the broods emerge asynchronously, the impact of another brood on the level of LMC experienced by offspring depends considerably on whether they are in the first or second brood to emerge $\left(h_{1}>h_{2}\right)$. For a female whose brood emerges first, the later brood primarily provides mating opportunities for her sons, rather than her daughters providing many mating opportunities for males from the later brood. Males from the later brood suffer greater competition for mates from males remaining in the patch, without the compensation of more females to copulate with.

The importance of asymmetrical LMC is increased by adaptive behavior in both males and females. Male behavior increased the likelihood of asymmetrical LMC because males preferentially remain on a patch when females are about to emerge from other hosts (van den Assem 1980b; fig. 5). Exactly how males assess the presence and developmental stage of wasps within hosts is unknown at present, as is how males specifically assess that there are females in the hosts. This also contrasts with the previous result that females appear to be unable to determine the sex of eggs laid by other females and adjust their offspring sex ratio accordingly (Werren 1984). Female behavior in- creases the likelihood of asymmetrical LMC because females preferentially oviposit on unparasitized hosts and avoid parasitized hosts (fig. 6A). This leads to the brood of a second female to visit a patch emerging later than the brood of the first female who visited the patch. Furthermore, field collections of hosts in bird nests can produce wasps with emergence times spread over more than 10 days (E. M. Sykes et al., unpublished data), more than setting the scene for complex patterns of asymmetrical LMC in natural conditions.

\section{Testing the Theory}

Our results confirm that female $N$. vitripennis are extremely plastic in their host choice, clutch size, and sex ratio responses. Females adjusted their host choice and clutch size behavior, as predicted by several previous models (Charnov and Stephens 1988; Godfray et al. 1991; Wilson 1994). Our results are also consistent with previous studies that indicate female assessment of the number of previously laid eggs; although the exact mechanism and degree of precision remain unclear, they seem to depend, in part, on the degree of oviposition asynchrony (Werren 1984; King and Skinner 1991). We also confirmed the affect of superparasitism on sex ratio (Werren 1980). 
Most importantly, females adjusted their offspring sex ratio in the direction predicted by our asymmetrical LMC model. Specifically, females laid a less female-biased sex ratio on a host if the other host on the patch had previously been parasitized, and they laid a less female-biased sex ratio on the parasitized host when they also laid eggs on an unparasitized host. This second result is counterintuitive from the viewpoint of standard LMC theory, in which the production of more offspring on a patch selects for a more female-biased sex ratio (Werren 1980; Frank 1985, 1987, 1998; Yamaguchi 1985; Stubblefield and Seger 1990). The reason for this difference is that females are producing different sex ratios on different hosts, with relatively more daughters on the unparasitized host, because the sons that they produce on the parasitized host will emerge first and have greater opportunity to mate with the females from both hosts, increasing their relative marginal fitness.

While our data provide qualitative support for the predictions of our model, they do not provide quantitative support. In particular, females produce a less biased sex ratio than predicted on unparasitized hosts, both when they do and when they do not lay eggs on the parasitized host on the patch. Possible explanations for this include that our laboratory estimates of the mating parameters are biased or that females have imperfect knowledge about the clutch size and sex ratio produced by the first female (i.e., limits on information processing). Alternatively, our model may have missed some important biological feature, such as the way that information is gradually obtained about the patch or the complications arising from having to simultaneously optimize host choice, clutch size, and sex ratio. Future empirical studies could vary the extent of asymmetrical LMC through factors such as the time between females visiting a patch or the number of parasitized and unparasitized hosts on a patch and test whether females adjusted their offspring sex ratios accordingly. However, it will also be important to develop theory further, in particular considering the optimization of host choice, clutch size, and sex ratio at the same time.

Our results illustrate two general points about testing evolutionary theory. First, the extent to which individuals can process relevant information about the environment appears to be a common constraint limiting the perfection of behavior (West and Sheldon 2002; Boomsma et al. 2003). Incorporating this into theory remains a major task. Second, even when data provide strong support for theory, there may be hidden behavioral complications. For example, with LMC theory, models that allow individuals to behave differently often lead to predictions that are quantitatively similar at the patch level to models that assume that all individuals behave the same (Charnov 1982; Taylor and Crespi 1994; Frank 1998). This is because the differences may cancel out-in this study because females are selected to produce more biased sex ratios on some hosts and less biased ones on others.

\section{Acknowledgments}

We are very grateful to L. Edwardson, A. Graham, and A. Robson for their diligent help in the laboratory and to two anonymous referees for the insightful comments that greatly improved the manuscript. We are also grateful to the Biotechnology and Biological Sciences Research Council, the Natural Environment Research Council, and the Royal Society for financial support.

\section{Literature Cited}

Abe, J., Y. Kamimura, H. Ito, H. Matsuda, and M. Shimada. 2003. Local mate competition with lethal male combat: effects of competitive asymmetry and information availability on a sex ratio game. Journal of Evolutionary Biology 16:607-613.

Boomsma, J. J., J. Nielsen, L. Sundström, N. J. Oldham, J. Tentschert, H. C. Petersen, and E. D. Morgan. 2003. Informational constraints on optimal sex allocation in ants. Proceedings of the National Academy of Sciences of the USA 100:8799-8804.

Charnov, E. L. 1982. The theory of sex allocation. Princeton University Press, Princeton, NJ.

Charnov, E. L., and D. W. Stephens. 1988. On the evolution of host selection in solitary parasitoids. American Naturalist 132:707-722.

Crawley, M. J. 2002. Statistical computing: an introduction to data analysis using S-Plus. Wiley, Chichester.

Drapeau, M. D., and J. H. Werren. 1999. Differences in mating behavior and sex ratio between three sibling species of Nasonia. Evolutionary Ecology Research 1:223-234.

Flanagan, K. E., S. A. West, and H. C. J. Godfray. 1998. Local mate competition, variable fecundity, and information use in a parasitoid. Animal Behaviour 56:191-198.

Frank, S. A. 1985. Hierarchical selection theory and sex ratios. II. On applying the theory, and a test with fig wasps. Evolution 39: 949-964.

- 1986. Hierarchical selection theory and sex ratios. I. General solutions for structured populations. Theoretical Population Biology 29:312-342.

- 1987. Variable sex ratio among colones of ants. Behavioral Ecology and Sociobiology 20:195-201.

. 1998. Foundations of social evolution. Princeton University Press, Princeton, NJ.

- 2002. A touchstone in the study of adaptation. Evolution 56:2561-2564.

Godfray, H. C. J. 1994. Parasitoids: behavioural and evolutionary ecology. Princeton University Press, Princeton, NJ.

Godfray, H. C. J., L. Partridge, and P. H. Harvey. 1991. Clutch size. Annual Review of Ecology and Systematics 22:409-429.

Greeff, J. M. 1997. Offspring sex allocation in externally ovipositing fig wasps with varying clutch size and sex ratio. Behavioral Ecology 8:500-505.

Hamilton, W. D. 1967. Extraordinary sex ratios. Science 156:477488.

. 1996. Narrow roads of gene land. I. Evolution of social behaviour. W. H. Freeman, Oxford. 
Hardy, I. C. W. 2002. Sex ratios: concepts and research methods. Cambridge University Press, Cambridge.

Herre, E. A. 1985. Sex ratio adjustment in fig wasps. Science 228: 896-898.

Herre, E. A., C. A. Machado, and S. A. West. 2001. Selective regime and fig wasp sex ratios: towards sorting rigor from pseudo-rigor in tests of adaptation. Pages 191-218 in S. Orzack and E. Sober, eds. Adaptionism and optimality. Cambridge University Press, Cambridge.

King, B. H., and S. W. Skinner. 1991. Proximal mechanisms of the sex ratio and clutch size responses of the wasp Nasonia vitripennis to parasitized hosts. Animal Behaviour 42:23-32.

King, B. H., M. L. Crowe, and S. W. Skinner. 1995. Effect of host density on offspring sex ratios and behavioral interactions between females in the parasitoid wasp Nasonia vitripennis (Hymenoptera, Pteromalidae). Journal of Insect Behavior 8:89-102.

Maynard Smith, J. 1982. Evolution and the theory of games. Cambridge University Press, Cambridge.

Michod, R. E., and W. D. Hamilton. 1980. Coefficients of relatedness in sociobiology. Nature 288:694-697.

Molbo, D., and E. D. Parker. 1996. Mating structure and sex ratio variation in a natural population of Nasonia vitripennis. Proceedings of the Royal Society of London B 263:1703-1709.

Nagelkerke, C. J. 1994. Simultaneous optimization of egg distribution and sex allocation in a patch-structured population. American Naturalist 144:262-284.

Nunney, L., and R. F. Luck. 1988. Factors influencing the optimum sex ratio in structured populations. Journal of Theoretical Biology 33:1-30.

Orzack, S. H. 1990. The comparative biology of second sex ratio evolution within a natural population of a parasitic wasp, Nasonia vitripennis. Genetics 124:385-396.

Orzack, S. H., E. D. Parker, and J. Gladstone. 1991. The comparative biology of genetic variation for conditional sex ratio behavior in a parasitic wasp, Nasonia vitripennis. Genetics 127:583-599.

Reece, S. E., D. M. Shuker, I. Pen, A. B. Duncan, A. Choudhary, C. M. Batchelor, and S. A. West. 2004. Kin discrimination and sex ratios in a parasitoid wasp. Journal of Evolutionary Biology 17: 208-216.

Seger, J., and J. W. Stubblefield. 1996. Optimization and adaptation. Pages 93-123 in M. R. Rose and G. V. Lauder, eds. Adaptation. Academic Press, San Diego, CA.

Shuker, D. M., and S. A. West. 2004. Information constraints and the precision of adaptation: sex ratio manipulation in wasps. Proceedings of the National Academy of Sciences of the USA 101: 10363-10367.

Shuker, D. M., S. E. Reece, P. R. Whitehorn, and S. A. West. $2004 a$. Sib-mating does not lead to facultative sex ratio adjustment in the parasitoid wasp, Nasonia vitripennis. Evolutionary Ecology Research 6:473-480.

Shuker, D. M., S. E. Reece, J. A. L. Taylor, and S. A. West. $2004 b$. Wasp sex ratio behaviour when females on a patch are related. Animal Behaviour 68:331-336.

Stubblefield, J. W., and J. Seger. 1990. Local mate competition with variable fecundity: dependence of offspring sex ratios on information utilization and mode of male production. Behavioral Ecology 1:68-80.
Suzuki, I., and Y. Iwasa. 1980. A sex ratio theory of gregarious parasitoids. Researches on Population Ecology 22:366-382.

Taylor, P. D. 1981. Intra-sex and inter-sex sibling interactions as sex determinants. Nature 291:64-66.

- 1993. Female biased sex ratios under local mate competition: an experimental confirmation. Evolutionary Ecology 7:306-308.

. 1996. Inclusive fitness arguments in genetic models of behavior. Journal of Mathematical Biology 34:654-674.

Taylor, P. D., and M. G. Bulmer. 1980. Local mate competition and the sex ratio. Journal of Theoretical Biology 86:409-419.

Taylor, P. D., and B. J. Crespi. 1994. Evolutionarily stable strategy sex ratios when correlates of relatedness can be assessed. American Naturalist 143:297-316.

van den Assem, J., F. Jachmann, and P. Simbolotti. 1980a. Courtship behaviour of Nasonia vitripennis (Hym. Pteromalidae): some qualitative, experimental evidence for the role of pheromones. Behaviour 75:301-307.

van den Assem, J., M. J. Gijswit, and B. K. Nubel. 1980b. Observations on courtship and mating strategies in a few species of parasitic wasps (Chalcidoidea). Netherlands Journal of Zoology 30:208-227.

Werren, J. H. 1980. Sex ratio adaptations to local mate competition in a parasitic wasp. Science 208:1157-1159.

1983. Sex ratio evolution under local mate competition in a parasitic wasp. Evolution 37:116-124.

- 1984. Brood size and sex ratio regulation in the parasitic wasp Nasonia vitripennis (Walker) (Hymenoptera: Pteromalidae). Netherlands Journal of Zoology 34:123-143.

West, S. A., and B. C. Sheldon. 2002. Constraints in the evolution of sex ratio adjustment. Science 295:1685-1688.

West, S. A., E. A. Herre, and B. C. Sheldon. 2000. The benefits of allocating sex. Science 290:288-290.

West, S. A., D. M. Shuker, and B. C. Sheldon. 2005. Sex ratio adjustment when relatives interact: a test of constraints on adaptation. Evolution 59:1211-1228.

Whiting, A. R. 1967. The biology of the parasitic wasp Mormoniella vitripennis. Quarterly Review of Biology 42:333-406.

Wilson, K. 1994. Evolution of clutch size in insects. II. A test of static optimality models using the beetle Callosobruchus maculatus (Coleoptera, Bruchidae). Journal of Evolutionary Biology 7:365-386.

Wilson, K., and I. C. W. Hardy. 2002. Statistical analysis of sex ratios: an introduction. Pages 48-92 in I. C. W. Hardy, ed. Sex ratios: concepts and research methods. Cambridge University Press, Cambridge.

Wylie, H. G. 1966. Some mechanisms that affect the sex ratio of Nasonia vitripennis (Walk.) (Hymenoptera: Pteromalidae) reared from superparasitized housefly pupae. Canadian Entomology 98: 645-653.

- 1976. Interference among females of Nasonia vitripennis (Hymenoptera: Pteromalidae), and its effect on sex ratios of their progeny. Canadian Entomology 108:655-661.

Yamaguchi, Y. 1985. Sex ratios of an aphid subject to local mate competition with variable maternal fecundity. Nature 318:460-462.

Associate Editor: Peter Nonacs Editor: Michael C. Whitlock 
(C) 2005 by The University of Chicago. All rights reserved.

\section{Appendix from D. M. Shuker et al., "Sex Ratios under Asymmetrical Local Mate Competition: Theory and a Test with Parasitoid Wasps" (Am. Nat., vol. 166, no. 3, p. 301)}

\section{Asymmetrical Local Mate Competition Theory}

We work with a patch-structured population with local mate competition and random dispersal of mated females. Each patch contains two hosts that are attacked by two females. Female $i(i=1,2)$ lays $c_{i j}$ eggs on host $j(j=$ $1,2)$ and has sex ratio $x_{i j}$ (proportion of sons). Sons compete to mate the emerging daughters, but because of asynchronous laying or emergence, the mating abilities of sons may vary accordingly. Specifically, female $i$ 's son that was born on host $j$ has relative ability $a_{i j k}$ to mate with a host- $k$ female. For example, $a_{121}$ is the host- 1 mating ability of female 1 's son born on host 2 .

The inclusive fitness of female $i$ is given by

$$
W_{i}=R_{f} v_{j} \sum_{j=1,2} c_{i j}\left(1-x_{i j}\right)+R_{m} v_{m} \sum_{k=1,2} \sum_{j=1,2} c_{i j} x_{i j} a_{i j k} Q_{k} .
$$

Here $R_{i}(i=f, m)$ is the relatedness of the mother to her sex- $i$ offspring, and $v_{i}$ is the sex- $i$ class reproductive value (Michod and Hamilton 1980; Taylor 1996). The quantity $Q_{k}$ is the average number of females mated per "unit male competitiveness" on host $k(k=1,2)$ :

$$
Q_{k}=\frac{\sum_{j=1,2} c_{j k}\left(1-x_{j k}\right)}{\sum_{i=1,2} \sum_{j=1,2} c_{i j} x_{i j} a_{i j k}} .
$$

We now consider the clutch sizes as given and look for equilibrium sex ratios $\hat{x}_{i j}$ by inspecting the selection differentials $\partial W_{i} / \partial x_{i j}$. Interior equilibria are given by

$$
\left.\frac{\partial W_{i}}{\partial x_{i j}}\right|_{x_{i j}=\hat{x}_{i j}}=0 .
$$

Evolutionary stability of equilibria was checked numerically by verifying that the $4 \times 4$ matrix of second-order derivatives $\partial^{2} W_{i} / \partial x_{i j}^{2}(i, j=1,2)$, evaluated at equilibrium, is a stability matrix (all eigenvalues have negative real part). Convergence stability was checked by simulating the standard evolutionary dynamics of the average population sex ratios,

$$
\frac{d \hat{x}_{i j}}{d t}=\left.\frac{\partial W_{i}}{\partial x_{i j}}\right|_{x_{i j}=\hat{x}_{i j}} .
$$

All equilibria were globally stable under this dynamic.

We assume a haplodiploid species; hence, $R_{m}=1$ and $v_{f}=2 v_{m}$. The remaining relatedness coefficient $R_{f}$ was handled in two ways, a "theoretical" way and an "empirical" way. Theoretically, given average probability $\bar{p}$ of sib mating, $R_{f}$ obeys the well-known formula

$$
R_{f}=\frac{1}{2-\bar{p}}
$$

(Taylor 1993). Assuming that the whole population consists of patches with two females using two hosts, this 
can be calculated as follows. The population-wide probability $p_{i k}$ that a daughter of female $i$ mates with a brother in host $k$ is given by

$$
p_{i k}=\frac{\sum_{j=1,2} c_{i j} \hat{x}_{i j} a_{i j k}}{\sum_{l=1,2} \sum_{j=1,2} c_{l j} \hat{x}_{l j} a_{l j k}} .
$$

The average proportion of sib mating is then the average of the $p_{i k}$, weighted by the appropriate number of daughters:

$$
\bar{p}=\frac{\sum_{i=1,2} \sum_{k=1,2} c_{i k}\left(1-\hat{x}_{i k}\right) p_{i k}}{\sum_{i=1,2} \sum_{k=1,2} c_{i k}\left(1-\hat{x}_{i k}\right)} .
$$

The empirical way to obtain numerical values for $R_{f}$ is to use field estimates of the inbreeding coefficient $F$, the probability that paternal and maternal alleles are identical by descent. This value of $F$ is then plugged into

$$
R_{f}=\frac{1+3 F}{2+2 F} \text {. }
$$

We used the estimate ( $F=0.31$ ) obtained by Molbo and Parker (1996). It turned out that the two ways of estimating $R_{f}$ yield nearly identical numerical results. We obtained solutions for the ESS sex ratios numerically; these computations were carried out with Maple, and the files are available upon request from I. Pen.

Finally, we point out the relationship between our model and several other well-known LMC models. Hamilton's classic LMC model with $N=2$ corresponds to our model with parameter values $c_{12}=c_{21}=0$, $c_{11}=c_{22}$, and $a_{i j k}=$ const. Suzuki and Iwasa's (1980) and Werren's (1980) superparasitism models, where two females attack a single host without competitive asymmetries between sons, are obtained by setting $c_{i 2}=0$ and $a_{111}=a_{211}$. Werren only presented the diploid solution for this situation-our model can be used to show that the haplodiploid version of Werren's result is given by

$$
\begin{aligned}
& \hat{x}_{11}=\frac{3}{28}(1+c), \\
& \hat{x}_{21}=\frac{3}{28}(1+1 / c),
\end{aligned}
$$

as long as $c=c_{21} / c_{11}$ is not too small or too large. Note that for $c=1$, this reduces to the standard haplodiploid result for two females on a patch, $\hat{x}_{11}=\hat{x}_{21}=3 / 14$, as obtained by Taylor and Bulmer (1980). Nunney and Luck's (1988) model incorporated asynchronous emergence into the classic LMC model, but they assumed that its effect was to reduce the effective number of foundresses (i.e., lower $N$ ) and that it did not lead to asymmetrical mate competition (i.e., $h_{1}=h_{2}$ ). The superparasitism model of Abe et al. (2003) assumed that all individuals emerge synchronously but that the competitive ability of the second female's sons could be reduced (i.e., $a_{211}=a_{212}=a_{221}=a_{222}$ and $a_{111}=a_{112}$ ), but it also presented results when it was assumed that the second female can detect the sex ratio of the first female. 